\title{
WEAK OPENNESS AND ALMOST OPENNESS
}

\author{
DAVID A. ROSE \\ Department of Mathematics \\ Francis Marion College \\ Florence, South Carolina 29501 \\ (Received June 29, 1983)
}

\begin{abstract}
Weak openness and almost openness for arbitrary functions between topological spaces are defined as duals to the weak continuity of Levine and the almost continuity of Husain respectively. Independence of these two openness conditions is noted and comparison is made between these and the almost openness of Singal and Singal. Some results dual to those known for weak continuity and almost continuity are obtained. Nearly almost openness is defined and used to obtain an improved link from weak continuity to almost continuity.
\end{abstract}

KEY WORDS AND PHRASES. Weak openness, almost openness, nearly almost openness. 2980 Mathematics Subject Classification Codes. 54 ClO

\section{INTRODUCTION.}

Throughout this paper, $X$ and $Y$ represent arbitrary topological spaces and $\mathrm{f}: \mathrm{X} \rightarrow \mathrm{Y}$ denotes an arbitrary function. Properties $\mathrm{P}$ and $\mathrm{Q}$ are said to be dual properties if and only if for each bijection $g, g$ has $P$ if and only if $g^{-1}$ has $Q$. Thus continuity is dual to openness and the closed graph property is a self-dual. Weak openness and almost openness are defined as natural duals to the weak continuity of Levine [1] and the almost continuity of Husain [2] respectively. Almost openness applied to homomorphisms between topological groups was used by L. G. Brown [3] to obtain a topological version of the classical open mapping theorem. A different almost openness was introduced by Singal and Singal [4] and in this paper is referred to as almost openness ( $S$ and $S$ ). After noting some relationships and independences between these, conditions are found for which each implies openness. Finally, nearly almost openness is defined and used to improve a result of [5]. In particular it is shown that every nearly almost open, weakly continuous function is almost continuous. 2. DEFINITIONS AND PRELIMINARIES.

For a subset $\mathrm{A}$ of a topological space, $\mathrm{Cl} \mathrm{A}$ and Int $\mathrm{A}$ denote the closure and interior of A respectively.

DEFINITION 1 (Levine [1]). A function $\mathrm{f}: \mathrm{X} \rightarrow \mathrm{Y}$ is weakly continuous if and only if for each point $x \in X$ and for each neighborhood $V$ of $f(x)$ there is a neighborhood $U$ of $\mathrm{x}$ such that $\mathrm{f}(\mathrm{U}) \subseteq \mathrm{C} 1 \mathrm{~V}$. 
THEOREM 1. (Levine [1]) A function $\mathrm{f}: \mathrm{X} \rightarrow \mathrm{Y}$ is weakly continuous if and only if $\mathrm{f}^{-1}(\mathrm{~V}) \subseteq$ Int $\mathrm{f}^{-1}(\mathrm{Cl} \mathrm{V})$ for each open subset $\mathrm{V}$ of $\mathrm{Y}$.

THEOREM 2. (Levine [1]) Every weakly continuous function $\mathrm{f}: \mathrm{X} \rightarrow \mathrm{Y}$ into a regular space $\mathrm{Y}$ is continuous.

DEFINITION 2. (Husain [2]) A function $\mathrm{f}: \mathrm{X} \rightarrow \mathrm{Y}$ is almost continuous if and only if for each $x \in X$ and for each neighborhood $V$ of $f(x), C 1 f^{-1}(V)$ is a neighborhood of $x$. THEOREM 3. A function $\mathrm{f}: \mathrm{X} \rightarrow \mathrm{Y}$ is almost continuous if and only if $\mathrm{f}^{-1}(\mathrm{~V}) \subseteq$ Int $\mathrm{Cl} \mathrm{f}^{-1}(\mathrm{~V})$ for each open subset $V$ of $Y$.

Theorems 1 and 3 motivate the following definitions of weak openness and almost openness respectively.

DEFINITION 3. A function $f: X \rightarrow Y$ is weakly open if and only if $f(U) \subseteq$ Int $f(C l U)$ for each open subset $U$ of $X$.

DEFINITION 4. A function $\mathrm{f}: \mathrm{X} \rightarrow \mathrm{Y}$ is almost open if and only if $\mathrm{f}(\mathrm{U}) \subseteq$ Int $\mathrm{Cl} f(\mathrm{U})$ for each open subset $U$ of $X$.

A different almost continuity which we call almost continuity ( $S$ and $S$ ) and its dual almost openness ( $S$ and $S$ ) were studied by Singal and Singal [4].

DEFINITION 5. (Singal and Singal [4]) A function $\mathrm{f}: \mathrm{X} \rightarrow \mathrm{Y}$ is [almost continuous ( $S$ and $S$ )] almost open ( $S$ and $S$ ) if and only if the [inverse] image under $f$ of every regular open set is open.

THEOREM 4. A function $\mathrm{f}: \mathrm{X} \rightarrow \mathrm{Y}$ is [almost continuous ( $\mathrm{S}$ and $\mathrm{S}$ )] almost open ( $\mathrm{S}$ and $\mathrm{S}$ ) if and only if $\left[f^{-1}(V) \subseteq\right.$ Int $f^{-1}($ Int $\left.C 1 V)\right] f(U) \subseteq$ Int $f($ Int $C 1 U)$ for each open subset $[\mathrm{V}$ of $\mathrm{Y}] \mathrm{U}$ of $\mathrm{X}$.

This is true since the interior of the closure of an open set is regular open. Theorem 4 makes the following clear.

COROLLARY. Almost openness ( $\mathrm{S}$ and $\mathrm{S}$ ) implies weak openness.

The following example shows that weak openness does not imply almost openness ( $S$ and $S$ ). EXAMPLE 1. Let $X=\{a, b, c\}, S=\{\emptyset, X,\{a\},\{c\},\{a, c\}\}$, and $T=\{0, X,\{b\},\{a, b\}$, $\{b, c\}\}$. Let $f:(X, S) \rightarrow(X, T)$ be the identity function. Then Int $f(\operatorname{Int} C 1\{a\})=\emptyset$ so that $f$ is not almost open ( $S$ and $S)$. But Int $f(C 1\{a\})=\{a, b\}$, Int $f(C 1\{c\})=$ $\{b, c\}$, and Int $f(C 1\{a, c\})=X$ so that $f$ is weakly open.

Examples 1 and 2 of [5] demonstrate the independence of almost openness and each of the conditions, weak openness and almost openness ( $S$ and $S$ ), and that each is weaker than openness since for any bijection $f: X \rightarrow Y$, $f$ satisfies one of these generalized openness conditions if and only if $\mathrm{f}^{-1}: \mathrm{Y} \rightarrow \mathrm{X}$ satisfies the corresponding generalized continuity condition.

THEOREM 5. ([5]) The function $\mathrm{f}: \mathrm{X} \rightarrow \mathrm{Y}$ is

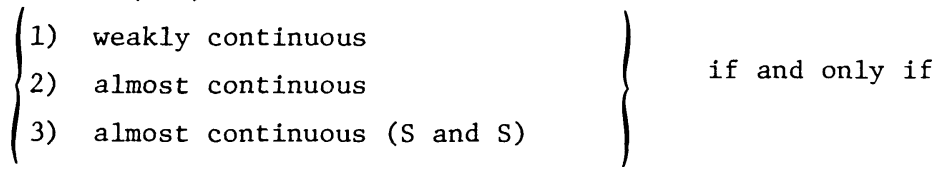


there is an open basis B for the topology on $Y$ such that for each $V \varepsilon B$,

$$
\left\{\begin{array}{ll}
\text { 1) } & \mathrm{f}^{-1}(\mathrm{~V}) \subseteq \text { Int } \mathrm{f}^{-1}(\mathrm{Cl} \mathrm{V}) \\
\text { 2) } & \mathrm{f}^{-1}(\mathrm{~V}) \subseteq \text { Int } \mathrm{Cl} \mathrm{f}^{-1}(\mathrm{~V}) \\
\text { 3) } & \mathrm{f}^{-1}(\mathrm{~V}) \subseteq \text { Int } \mathrm{f}^{-1}(\text { Int } \mathrm{Cl} \mathrm{V})
\end{array}\right\} \text {. }
$$

THEOREM 6. The function $\mathrm{f}: \mathrm{X} \rightarrow \mathrm{Y}$ is

$$
\left\{\begin{array}{ll}
1) & \text { weakly open } \\
2 & \text { almost open } \\
3) & \text { almost open (S and S) }
\end{array}\right\} \text { if and only if }
$$

there is an open basis A for the topology on X such that for each $U \varepsilon A$,

$$
\left\{\begin{array}{l}
\text { 1) } \mathrm{f}(\mathrm{U}) \subseteq \text { Int } \mathrm{f}(\mathrm{Cl} \mathrm{U}) \\
\text { 2) } \mathrm{f}(\mathrm{U}) \subseteq \text { Int } \mathrm{Cl} \mathrm{f}(\mathrm{U}) \\
\text { 3) } \mathrm{f}(\mathrm{U}) \subseteq \text { Int } \mathrm{f}(\text { Int } \mathrm{Cl} \mathrm{U})
\end{array}\right\}
$$

The necessity of theorems 5 and 6 is clear. For the sufficiency of each recall that each open set is a union of basic open sets and functions and inverse functions preserve unions. Further, for any family of subsets of a topological space, the union of the interiors of the members is contained in the interior of the union of the members and also the union of the closures of the members is contained in the closure of the union of the members.

3. DUAL RESULTS AND APPLICATIONS.

Theorems $A$ and $B$ concerning a function $f: X \rightarrow Y$ are said to be dual results if all conditions on $f$, either assumed or concluded, in theorem $A$ are replaced by dual conditions in Theorem $B$ and the domain and range conditions are interchanged between the two theorems. For example, theorems 5 and 6 above are dual results. We now dualize Theorem 2.

THEOREM 7. If $\mathrm{X}$ is regular and $\mathrm{f}: \mathrm{X} \rightarrow \mathrm{Y}$ is weakly open then $\mathrm{f}$ is open.

PROOF. Let $W$ be a nonempty open subset of $X$. For each $x \in W$, let $U(x)$ be an open set such that $\mathrm{x} \varepsilon \mathrm{U}(\mathrm{x}) \subseteq \mathrm{Cl} \mathrm{U}(\mathrm{x}) \subseteq \mathrm{W}$. Then $\mathrm{W}=\bigcup\{\mathrm{U}(\mathrm{x}): \mathrm{x} \varepsilon \mathrm{W}\}=\bigcup\{\mathrm{Cl} U(\mathrm{x}): \mathrm{x} \varepsilon \mathrm{W}\}$, and $f(W)=\bigcup\{f(U(x)): x \in W\} \subseteq \bigcup\{$ Int $f(C 1 U(x)): x \varepsilon W\} \subseteq$ Int $f(U\{C 1 U(x): x \varepsilon W\})=$ Int $\mathrm{f}(\mathrm{W})$.

For a topological space (X, T), let (X, T') be the semiregular space with topology $\mathrm{T}^{\prime}$ generated by the regular open sets in $\mathrm{T}$.

THEOREM 8. A function $\mathrm{f}:(\mathrm{X}, \mathrm{T}) \rightarrow \mathrm{Y}$ is almost open ( $\mathrm{S}$ and $\mathrm{S}$ ) if and only if $f:\left(X, T^{\prime}\right) \rightarrow Y$ is open.

PROOF. For the sufficiency, let $U \varepsilon T$. Then Int $C l U \varepsilon T^{\prime}$ so that $f(U) \subseteq f($ Int $C l U)=$ Int $\mathrm{f}$ (Int $\mathrm{C} 1 \mathrm{U})$. For the necessity, let $\mathrm{U} \in \mathrm{T}$ be regular open. Then $\mathrm{f}(\mathrm{U}) \subseteq$ Int $\mathrm{f}($ Int $\mathrm{C} 1 \mathrm{U})=$ Int $\mathrm{f}(\mathrm{U})$ so that $\mathrm{f}:\left(\mathrm{X}, \mathrm{T}^{\prime}\right) \rightarrow \mathrm{Y}$ is open. 
Theorem 8 is the dual to a characterization of almost continuity (S and S) noted by Long and Herrington [6].

In [5] a function $\mathrm{f}: \mathrm{X} \rightarrow \mathrm{Y}$ was defined to be subweakly continuous if there is an open basis $B$ for the topology on $Y$ such that for each $V \varepsilon B, C 1 f^{-1}(V) \subseteq f^{-1}(C 1 V)$. It was also shown that almost continuity and subweak continuity jointly imply weak continuity. These results will now be dualized as well as a closed graph theorem of Long and McGehee [7].

THEOREM 9. If the function $\mathrm{f}: \mathrm{X} \rightarrow \mathrm{Y}$ is almost open and if for each set $\mathrm{U}$ from some open basis for the topology on $\mathrm{X}, \mathrm{Cl} \mathrm{f}(\mathrm{U}) \subseteq \mathrm{f}(\mathrm{Cl} \mathrm{U})$, then $\mathrm{f}$ is weakly open.

PROOF. For any basic open set $\mathrm{U}, \mathrm{f}(\mathrm{U}) \subseteq$ Int $\mathrm{C} 1 \mathrm{f}(\mathrm{U}) \subseteq$ Int $\mathrm{f}(\mathrm{C} 1 \mathrm{U})$. By Theorem 6 , $\mathrm{f}$ is weakly open.

Example 2 below shows that almost openness cannot be dropped in Theorem 9 .

THEOREM 10. If $\mathrm{X}$ is a locally compact regular space and the almost open function $\mathrm{f}: \mathrm{X} \rightarrow \mathrm{Y}$ has a closed graph then $\mathrm{f}$ is open.

PROOF. Let $U$ be a basic open subset of $X$ having compact closure. Then $f(C 1 U)$ is closed so that $\mathrm{Cl} f(\mathrm{U}) \subseteq \mathrm{f}(\mathrm{Cl} \mathrm{U})$. By theorems 9 and $7, \mathrm{f}$ is open.

A space is strongly locally compact if each point has a closed compact neighborhood. Such a space need not be regular. In [8] it is shown that any almost continuous closed graph function into a strongly locally compact space is continuous. Does the dual result hold?

QUESTION 1. Does Theorem 10 hold if $\mathrm{X}$ is only assumed to be strongly locally compact?

In [5] it is shown that a function $\mathrm{f}: \mathrm{X} \rightarrow \mathrm{Y}$ is weakly continuous if and only if $\mathrm{C} 1 \mathrm{f}^{-1}(\mathrm{~V}) \subseteq \mathrm{f}^{-1}(\mathrm{C} 1 \mathrm{~V})$ for each open subset $\mathrm{V}$ of $\mathrm{Y}$. The following example shows the dual is not true. In fact, weak openness is independent of the condition: $\mathrm{Cl} f(\mathrm{U}) \subseteq \mathrm{f}(\mathrm{Cl} \mathrm{U})$ for each open subset $\mathrm{U}$ of $\mathrm{X}$.

EXAMPLE 2. Let $\mathrm{R}$ be the usual space of real numbers and let $M$ be the Michael 1 ine, i.e. the space $M$ is the set of real numbers with topology $T=\{U U H$ : $U$ belongs to the usual topology on $R$ and $H \subseteq R-Q$ where $Q$ is the set of rational real numbers\}. Define $1_{M}: R \rightarrow M$ to be the identity function and let $f=1_{M} \mid Q$ and $g=1_{M} \mid(R-Q)$ be restrictions of $l_{M}$. Then $f: Q \rightarrow M$ satisfies the condition: $C 1 f(U) \subseteq f(C 1$ f $)$ for each open subset $U$ of $Q$. But $f$ is not weakly open since $f(Q)$ is not open in $M$. Further, $g:(R-Q) \rightarrow M$ is weakly open but since $g(R-Q)$ is not closed, $g$ does not satisfy the condition: $\mathrm{C} 1 \mathrm{~g}(\mathrm{U}) \subseteq \mathrm{g}(\mathrm{Cl} \mathrm{U})$ for each open subset $\mathrm{U}$ of $(\mathrm{R}-\mathrm{Q})$.

QUESTION 2. Clearly $\mathrm{f}: \mathrm{X} \rightarrow \mathrm{Y}$ is weakly open and satisfies $\mathrm{Cl} f(\mathrm{U}) \subseteq \mathrm{f}(\mathrm{Cl} \mathrm{U}) \mathrm{for}$ each open $U \subseteq X$ implies $f(X)$ is clopen. When $f(X)$ is clopen or in particular for a surjection $\mathrm{f}: \mathrm{X} \rightarrow \mathrm{Y}$, is weak openness related to the condition: $\mathrm{Cl} f(\mathrm{U}) \subseteq f(\mathrm{Cl} U)$ for each open $U \subseteq X$ ? 
In [5] the following comparison of continuity and almost continuity was given. A function $f: X \rightarrow Y$ is (almost) continuous if and only if $f(C l U) \subseteq C 1 f(U)$ for each (open) subset $U$ of $X$. The dual yields the following comparison of open and almost open functions.

THEOREM 11. A function $\mathrm{f}: \mathrm{X} \rightarrow \mathrm{Y}$ is (almost) open if and only if $\mathrm{f}^{-1}(\mathrm{Cl} \mathrm{V}) \subseteq \mathrm{Cl} \mathrm{f}^{-1}(\mathrm{~V})$ for each (open) subset $\mathrm{V}$ of $\mathrm{Y}$.

PROOF. In [5] this characterization for almost open functions was proven. Long and Carnahan [9] showed that $\mathrm{f}: \mathrm{X} \rightarrow \mathrm{Y}$ is open implies $\mathrm{f}^{-1}(\mathrm{Cl} \mathrm{V}) \subseteq \mathrm{Cl} \mathrm{f}^{-1}(\mathrm{~V})$ for every $\mathrm{V} \subseteq \mathrm{Y}$, and only the converse remains to be shown. Suppose $\mathrm{f}^{-1}(\mathrm{Cl} \mathrm{V}) \subseteq \mathrm{Cl} \mathrm{f}^{-1}(\mathrm{~V}) \mathrm{for}^{-1}$ every $\mathrm{V} \subseteq \mathrm{Y}$. Let $\mathrm{U}$ be an open subset of $\mathrm{X}$ and let $\mathrm{C}=\mathrm{Y}-\mathrm{f}(\mathrm{U})$. Then $\mathrm{U} \cap \mathrm{f}^{-1}((\mathrm{Cl} \mathrm{C}) \cap$ $\mathrm{f}(\mathrm{U})) \subseteq \mathrm{U} \cap \mathrm{f}^{-1}(\mathrm{Cl} C) \subseteq \mathrm{U} \cap \mathrm{Cl} \mathrm{f}^{-1}(\mathrm{C}) \subseteq \mathrm{U} \cap(\mathrm{X}-\mathrm{U})=\emptyset$. But $\mathrm{U} \cap \mathrm{f}^{-1}((\mathrm{Cl} C) \cap \mathrm{f}(\mathrm{U}))=\emptyset$ implies $\mathrm{f}^{-1}((\mathrm{Cl} C) \cap \mathrm{f}(\mathrm{U}))=\emptyset$ which implies that $(\mathrm{C} 1 \mathrm{C}) \cap \mathrm{f}(\mathrm{U})=\emptyset$. Thus $\mathrm{Cl} C \subseteq \mathrm{C}$ and $\mathrm{C}$ is closed so that $\mathrm{f}(\mathrm{U})$ is open.

\section{NEARLY ALMOST OPEN FUNCTIONS.}

In [5] it is shown that for a weakly continuous function to be almost continuous, it is sufficient that the function be almost open. Actually, it is sufficient to assume a condition weaker than almost openness, defined below.

DEFINITION 7. A function $\mathrm{f}: \mathrm{X} \rightarrow \mathrm{Y}$ is nearly almost open if and only if there is an open basis $B$ for the topology on $Y$ such that $f^{-1}(C l V) \subseteq C l f^{-1}(V)$ for each $V \varepsilon B$. From Theorem 11 it is clear that each almost open function is nearly almost open. The following example shows that a nearly almost open function need not be almost open.

EXAMPLE 3. Let $R$ be the set of real numbers and let $Z \subseteq R$ be the set of integers. Let $X=R$ be given the smallest extension of the usual topology for which $Z$ is open and let $\mathrm{Y}=\mathrm{R}$ have the usual topology and let $\mathrm{f}: \mathrm{X} \rightarrow \mathrm{Y}$ be the identity function. Let $B$ be the open basis for the usual topology on $Y$ containing all open intervals $(a, b)$ such that card $((a, b) \cap Z) \leq 1$, and $\{a, b\} \cap Z=\emptyset$. Then for each $V=(a, b) \varepsilon B, f^{-1}(C 1 V)=$ $[a, b]=C 1 f^{-1}(V)$, so that $f$ is nearly almost open. But if $W=R-Z$, $W$ is a dense open subset of $Y$ and $W$ is a closed proper subset of $X$ so that $f^{-1}(C 1 W)=f^{-1}(Y)=$ $\mathrm{X} \nsubseteq \mathrm{W}=\mathrm{Cl} \mathrm{W}=\mathrm{C} 1 \mathrm{f}^{-1}(\mathrm{~W})$. Hence $\mathrm{f}$ is not almost open.

Combining Theorem 10 with Definition 7 yields: the function $f: X \rightarrow Y$

$$
\begin{aligned}
& \text { is }\left\{\begin{array}{ll}
\text { 1) } & \text { open } \\
\text { 2) } & \text { almost open } \\
3) & \text { nearly almost open }
\end{array}\right\} \quad \text { if and only if } \\
& \mathrm{f}^{-1}(\mathrm{Cl} \mathrm{V}) \subseteq \mathrm{Cl} \mathrm{f}^{-1}(\mathrm{~V})\left\{\begin{array}{ll}
1) & \text { for each } \mathrm{V} \subseteq \mathrm{Y} \\
2) & \text { for each open } \mathrm{V} \subseteq \mathrm{Y} \\
3) & \text { for each basic open } \mathrm{V} \varepsilon \mathrm{B} \text { for some } \\
& \text { open basis } \mathrm{B} \text { for the topology on } \mathrm{Y}
\end{array}\right\}
\end{aligned}
$$


If a function $\mathrm{f}: \mathrm{X} \rightarrow \mathrm{Y}$ is either 1) almost open and subweakly continuous or 2) nearly almost open and weakly continuous, there is an open basis B for the topology on $\mathrm{Y}$ such that $\mathrm{f}^{-1}(\mathrm{Cl} \mathrm{V})=\mathrm{Cl} \mathrm{f}^{-1}(\mathrm{~V})$ for each $\mathrm{V} \varepsilon \mathrm{B}$. In this case Int $\mathrm{f}^{-1}(\mathrm{Cl} \mathrm{V})=\operatorname{Int} \mathrm{Cl} \mathrm{f}^{-1}(\mathrm{~V})$ for basic open sets $V$ so that $f$ is weakly continuous if and only if $f$ is almost continuous by Theorem 5. This proves the following slight improvement of Theorem 12 of $[5]$.

THEOREM 12. If the function $\mathrm{f}: \mathrm{X} \rightarrow \mathrm{Y}$ is nearly almost open and weakly continuous then $\mathrm{f}$ is almost continuous.

Example 4 of [5] shows that weak continuity cannot be reduced to subweak continuity in Theorem 12 even if $\mathrm{f}$ is open. For the function of example 4 of [5] is subweakly continuous and open but not weakly continuous, and thus by the above discussion not almost continuous. (Also a subweakly continuous almost continuous function must be weakly continuous.)

QUESTION 3. Noiri [10] has shown that almost open weakly continuous functions are almost continuous ( $S$ and $S$ ). Does this hold if almost openness is replaced by nearly almost openness?

\section{REFERENCES}

1. LEVINE, Norman A Decomposition of Continuity in Topological Spaces, Amer. Math. Monthly 68 (1961), 44-46.

2. HUSAIN, T. Almost Continuous Mappings, Prace Mat. 10 (1966), 1-7.

3. BROWN, L.G. Topologically Complete Groups, Proc. Amer. Math. Soc. 35 (1972), 593-600.

4. SINGAL, M.K. and SINGAL, Asha Rani Almost-Continuous Mappings, Yokohama Math. Journal 16 (1968), 63-73.

5. ROSE, D.A. Weak Continuity and Almost Continuity, Int. J. Math. Sci, to appear.

6. LONG, Paul E. and HERRINGTON, Larry L. Properties of Almost-Continuous Functions, Bo11. Un. Mat. Ita1. 10 (1974), 336-342.

7. LONG, Paul E. and McGEHEE, Earl E., Jr. Properties of Almost Continuous Functions, Proc. Amer. Math. Soc. 24 (1970), 175-180.

8. ROSE, David Alon On Levine's Decomposition of Continuity, Canad. Math. Bu11. 21 (1978), 477-481.

9. LONG, Paul E. and CARNAHAN, Donald A. Comparing Almost Continuous Functions, Proc. Amer. Math. Soc. 38 (1973), 413-418.

10. NOIRI, Takashi A Note on n-Continuous Functions, J. Korean Math. Soc. 18 $(1981 / 82)$, No. 1, 37-42. 


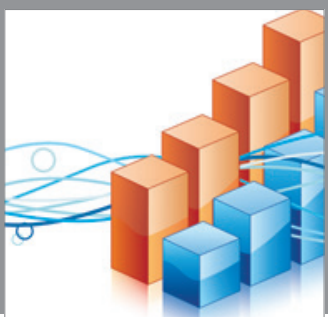

Advances in

Operations Research





\section{The Scientific} World Journal
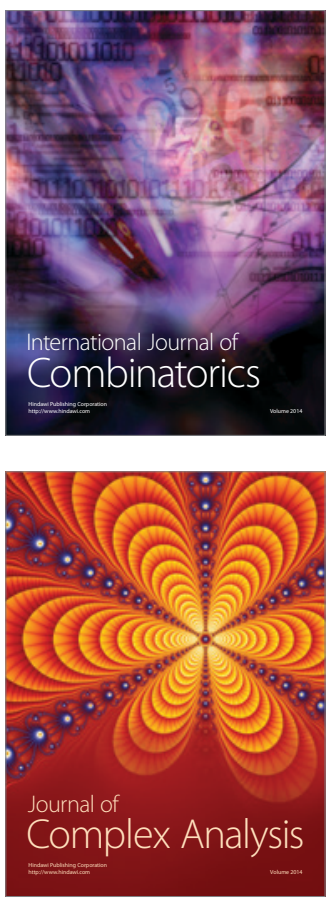

International Journal of

Mathematics and

Mathematical

Sciences


Journal of

Applied Mathematics
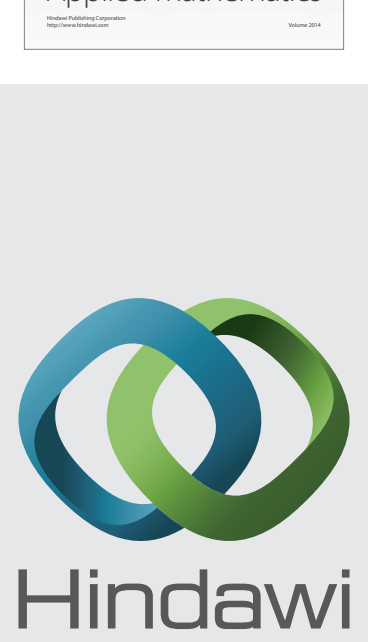

Submit your manuscripts at http://www.hindawi.com
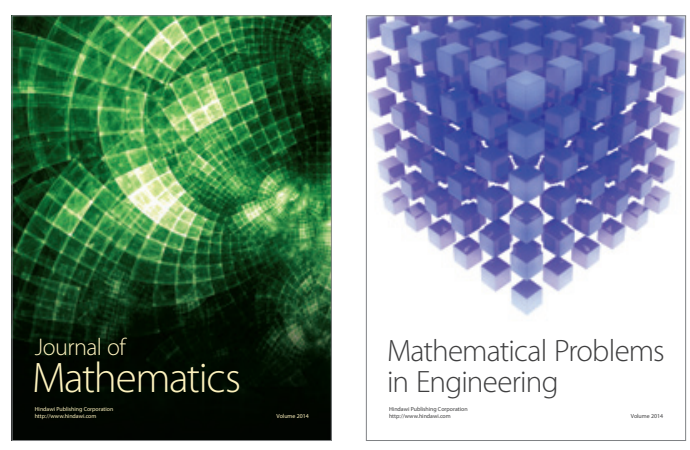

Mathematical Problems in Engineering
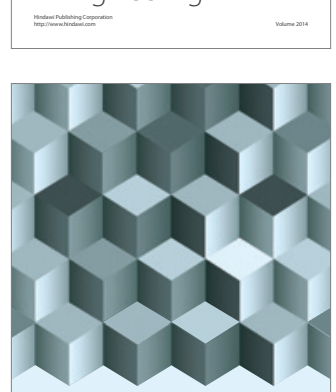

Journal of

Function Spaces
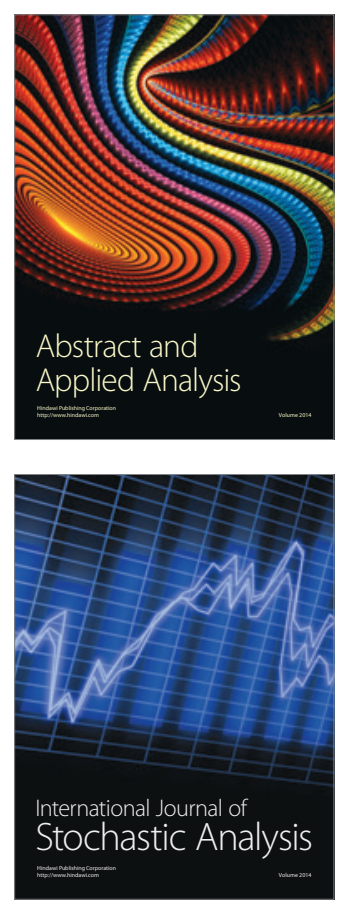

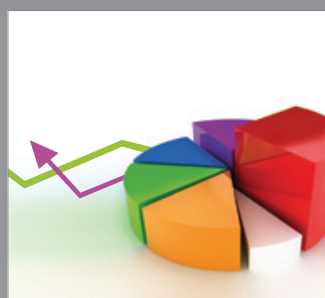

ournal of

Probability and Statistics

Promensencen
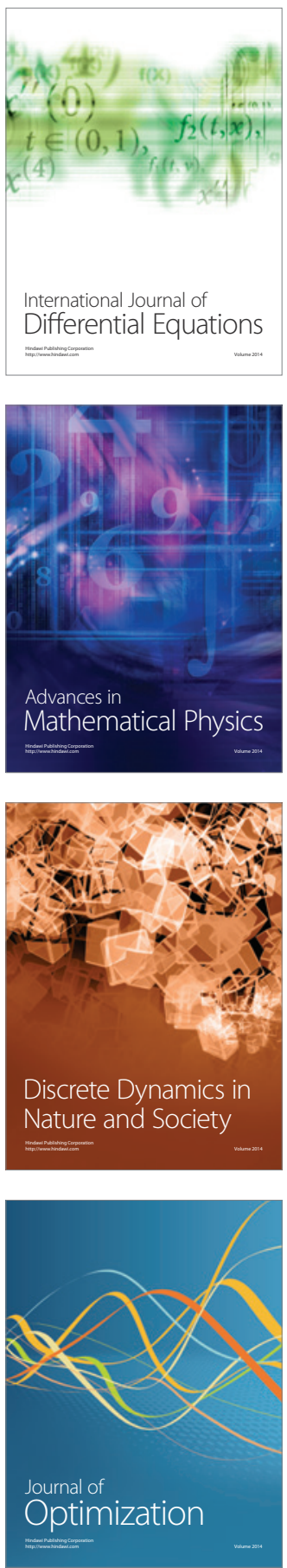